\title{
A convenient dicarboxylation of ortho-terphenyl
}

\author{
E-Joon Choi, ${ }^{\text {a,b }}$ Kyung Min Park ${ }^{\mathrm{b}}$ and Edward T. Samulski ${ }^{\mathrm{a}, *}$ \\ ${ }^{a}$ Department of Chemistry, University of North Carolina at Chapel Hill, \\ Chapel Hill, North Carolina 27599-3290, USA \\ ${ }^{b}$ Department of Polymer Science and Engineering, Kumoh National Institute of Technology, \\ Kumi, Kyungbuk 730-701, Korea \\ et@unc.edu
}

\section{Dedicated to William (Bill) F. Bailey on the occasion of his $65^{\text {th }}$ birthday}

DOI: http://dx.doi.org/10.3998/ark.5550190.0012.518

\begin{abstract}
We report a facile dicarboxylation of ortho-terphenyl, an important moiety for preserving conjugation in organic light-emitting diodes (OLEDs) where linear conjugated structures lead to intractable solids.
\end{abstract}

Keywords: Carboxylation, organic light-emitting diode, OLED

\section{Introduction}

Heeger, MacDiarmid and Shirakawa were awarded the 2000 Nobel Prize in Chemistry for their work on electrically conducting polymers. Such polymers as well as conducting low molar mass molecules typically employ conjugated aromatic rings to establish delocalization, a prerequisite for electron/hole transport. Moreover, the number of rings and their substitution patterns enable one to tune the band gap separating the HOMO from the LUMO in organic light emitting diode (OLED) and organic photovoltaic (OPV) materials ${ }^{1,2}$. Canonical examples include poly $(p$ phenylenes) and poly(2,5-thiophenes). However, extended conjugation leads to intractable materials; "brick dust" is the colloquial expression for these infusible and insoluble materials. For example, oligomers of $p$-phenylenes I and 2,5-thiophenes II become intractable for $n \approx 6$. The prototypical donor component in OPV solar cells is poly(3-hexylthiophene) known as P3HT III $\left(\mathrm{R}=-\mathrm{C}_{6} \mathrm{H}_{13}\right)$, but the (preferably regio-regular ${ }^{3}$ ) sidechains of P3HT, while increasing solubility, are deleterious as they dilute the content of conjugated core in condensed phases. On the other hand, alternating 2,5-thiophene with $p$-phenylene in five-ring oligomers IV makes the polyaromatics more tractable and dramatically affects the band gap (increased coplanarity of successive rings across the phenyl-thiophene covalent $\mathrm{C}-\mathrm{C}$ bond accrues because of reduced steric interactions between the hydrogen atoms on neighboring heterocycle) $)^{4}$, the usual way to 
circumvent the tractability issue is to attach sidechain substituents. One way to maintain some degree of conjugation, while retaining tractability and high aromatic content, is to incorporate ortho-substituted linkages. We recently introduced $o$-terphenyl into the so-called mesogenic core of all-aromatic liquid crystals converting, for example, the seven-ring, linear oligomer into a low-melting, glass-forming solid $\mathbf{V}^{5}$. Herein, we report a facile route to functionalize $o$-terphenyl for incorporation into tractable, ester-linked, and aromatic-rich materials.

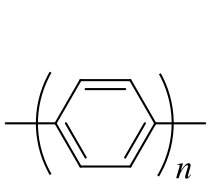

I

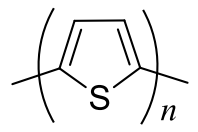

II

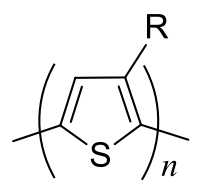

III

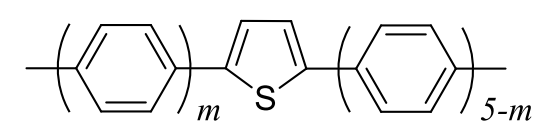

IV

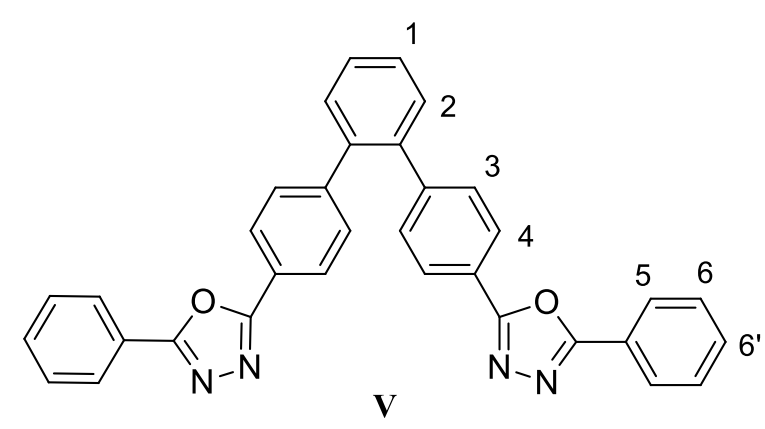

\section{Scheme 1}

\section{Results and Discussion}

Terphenyl isomers are commercially available, and thus dicarboxylation is a viable and facile way to functionalize them. In particular, 4,4"-terphenyldicarboxy acids are useful for polycondensation to wholly-aromatic polyamides ${ }^{6}$, polyesters etc. In the literature, methods for synthesizing 4,4"-terphenyldicarboxy acids with $o$-, $m$ - or $p$-substitution position have been individually reported. The 4,4"-p-terphenyldicarboxylic acid ${ }^{7}$ was simply synthesized by dicarboxylation reaction of $p$-terphenyl with oxalyl chloride and aluminum chloride using carbon disulfide as a solvent in a high yield. Since the reaction of $m$-terphenyl with oxalyl chloride in the presence of $\mathrm{AlCl}_{3}$ afforded a mixture of mono- and dicarboxylic acids that are insoluble in most organic solvents, the $4,4^{\prime \prime}-m$-terphenyldicarboxylic acid ${ }^{8}$ was synthesized by hydrolysis of the diester prepared from methanol using $\mathrm{SOCl}_{2}$. On the other hand, 4,4"-o-terphenyldicarboxy acid $^{9}$ was prepared from $4,4^{\prime \prime}$-dibromo- $O$-terphenyl ${ }^{10}$ by a Grignard reaction and the latter can be prepared from 2-iodo-4'-methylbiphenyl by cross-coupling chemistry. Alternatively, oxidation of 
$4,4^{\prime \prime}$-dimethyl-o-terphenyl ${ }^{11}$ can be used for the preparation of the 4,4 "-o-terphenyldicarboxylic acid.

In this paper we report that the conventional synthetic route to $4,4{ }^{\prime \prime}-o$-terphenydicarboxylic acid (prepared by a dicarboxylation with excess oxalyl chloride and aluminum chloride in carbon disulfide; see Scheme 2) is in fact much more convenient than the synthetic route based on a Grignard reaction of the dibromide. Interestingly, at the first stage of our dicarboxylation reaction, the expected dicarboxylated product was not produced. Instead the acid anhydride between 4,4"-o-terphenyldicarboxylic acid and excess oxalyl chloride was obtained quantitatively with the trace amount of a tri-carboxylated by-product. Subsequent hydrolysis of the anhydride intermediate gave a better than $90 \%$ yield of the 4,4" $-o$-terphenydicarboxylic acid. The acid anhydride: $\mathrm{mp} 120{ }^{\circ} \mathrm{C}$; TLC (silica gel, hexane/ethyl acetate $=5: 1, \mathrm{v} / \mathrm{v}$ ), $\mathrm{R}_{\mathrm{f}} 0.70 ;{ }^{1} \mathrm{H}$ NMR (400 MHz, DMSO-d $d_{6} \delta .80(\mathrm{~d}, J 8.4 \mathrm{~Hz}, 4 \mathrm{H}), 7.50(\mathrm{~m}, J 31.5 \mathrm{~Hz}, 4 \mathrm{H}), 7.21$ (d, $J=8.5$ $\mathrm{Hz}, 4 \mathrm{H})$. 4,4"-o-Terphenyldicarbonyl dichloride was readily prepared from the 4,4"-oterphenyldicarboxylic acid by using $\mathrm{SOCl}_{2}$ and converted to the corresponding esters by reaction with octyl- or heptyloxy-phenol. An alternate route using $N, N^{\prime}$-dicyclohexylcarbodiimide (DCC) is also viable. In Figure 1a, the tri-substituted byproduct can be excluded by the observed symmetric resonance pattern for 2. This symmetry is retained in the NMR spectra of ultimate target molecules such as V (Figure 1b). Figure 2 exhibits the characteristic resonances of the 1and 2-protons in 4 make the assignment of $\mathrm{nmr}$ spectra of esters straightforward.
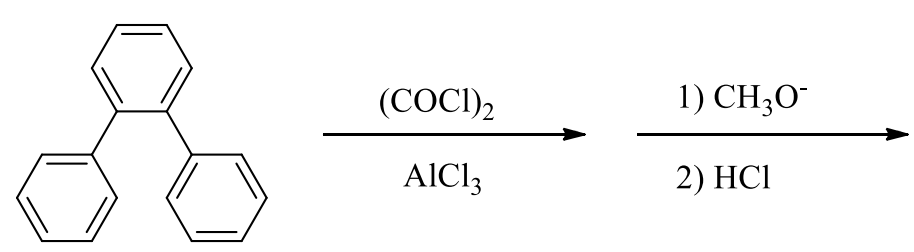

1

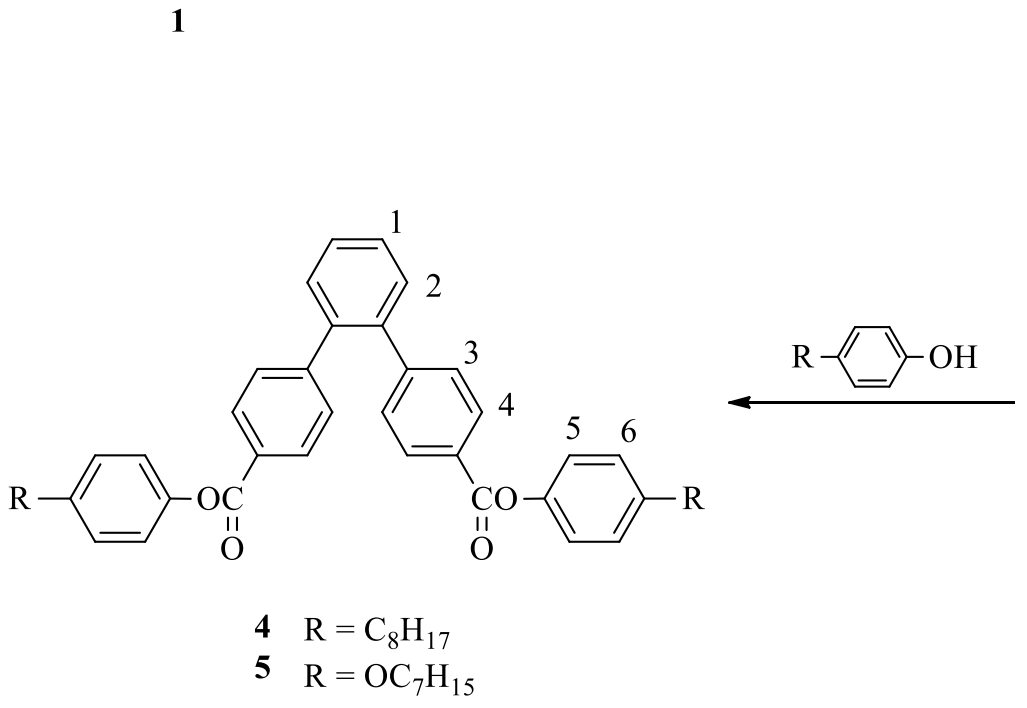

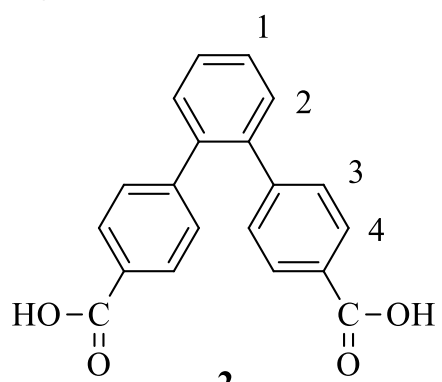

2 $\mathrm{SOCl}_{2}$

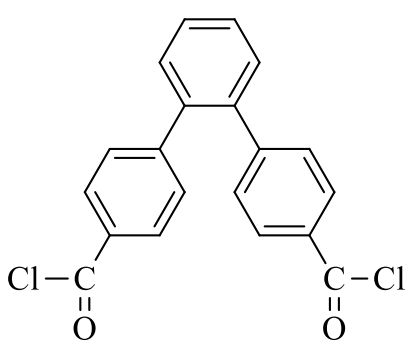

3

\section{Scheme 2}




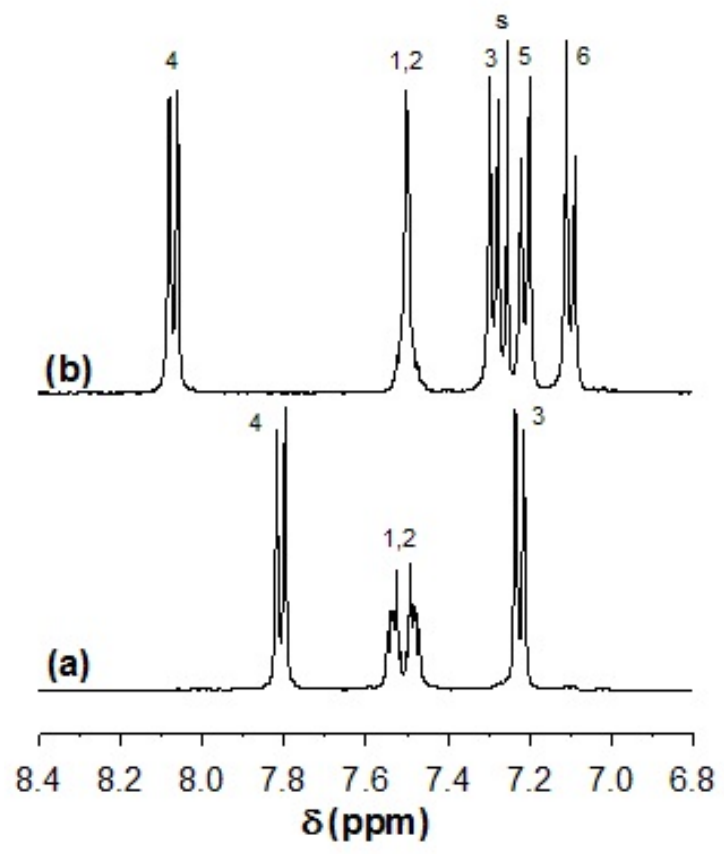

Figure 1. ${ }^{1} \mathrm{H}$ NMR spectra of (a) 2 and (b) $\mathbf{V}$ at $400 \mathrm{MHz}$.

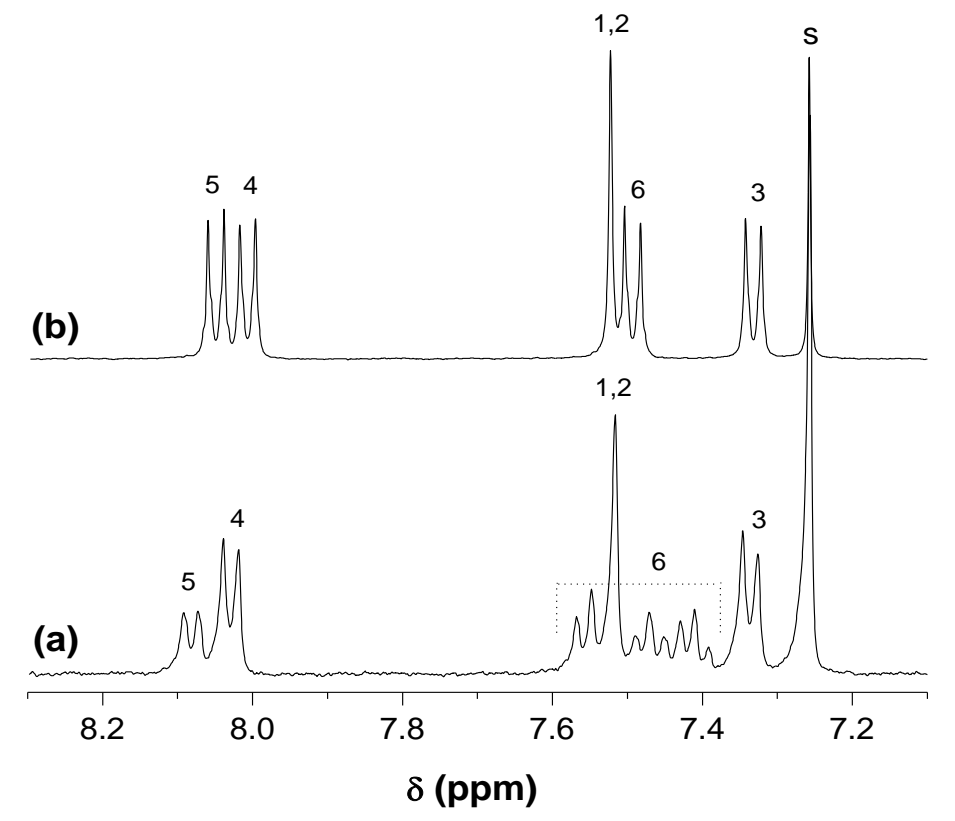

Figure 2. ${ }^{1} \mathrm{H}$ NMR spectra of (a) 4 and (b) 5 at $400 \mathrm{MHz}$. 


\section{Experimental Section}

General. IR and NMR spectra were obtained by Thermo scientific Nicolet 6700 FT/IR and Bruker $400 \mathrm{MHz}$ NMR spectrometer, respectively. Elemental analyses were performed with a Thermofinnigan EA1108. The melting temperatures were determined by a differential scanning calorimeter (Seiko DSC 220C) at a heating rate of $10^{\circ} \mathrm{C} / \mathrm{min}$ or a capillary MP apparatus.

4,4"-o-Terphenydicarboxylic acid (2). A one-neck flask (200 mL) equipped with Claisen adapter and Ar-gas inlet was charged with of carbon disulfide $(70 \mathrm{~mL}), o$-terphenyl $(7.6 \mathrm{~g}, 0.033$ mmol), and oxalyl chloride ( $25 \mathrm{~g}, 0.20 \mathrm{~mol})$. This solution was cooled to $0{ }^{\circ} \mathrm{C}$ and anhydrous aluminum chloride $(10 \mathrm{~g}, 0.75 \mathrm{~mol})$ was added in several batches. After the obtained dark-brown mixture was stirred for $1 \mathrm{~h}$ at $0{ }^{\circ} \mathrm{C}$, additional aluminum chloride (10 g, $\left.0.75 \mathrm{~mol}\right)$ was added. Then the ice-bath was removed, and stirring was continued overnight at room temperature. The mixture was poured slowly into a mixture of dilute hydrochloric acid with crushed ice. The carbon disulfide was evaporated under reduced pressure. The obtained pale yellow solid was filtered, washed with dilute hydrochloric acid and water, which was an anhydride of the desired dicarboxylic acid. In order to decompose the anhydride, it was treated with $10 \% \mathrm{KOH}$ solution in methanol. The obtained potassium carboxylate was acidified by conc. $\mathrm{HCl}$, using $\mathrm{pH}$ paper as indicator. This crude product was washed with water, recrystallized from a mixture of ethanol and water $(7: 1 \mathrm{v} / \mathrm{v})$, and dried under vacuum at $60{ }^{\circ} \mathrm{C}: \mathrm{mp} 345^{\circ} \mathrm{C}$ (decomp.) (Lit. ${ }^{4} 317-320{ }^{\circ} \mathrm{C}$ ); ${ }^{1} \mathrm{H}$ NMR (400 MHz, DMSO-d $\left.)\right) \delta 12.94\left(\mathrm{~s}, 2 \mathrm{H}, \mathrm{ArCO}_{2} \mathrm{H}\right), 7.81(\mathrm{~d}, J 8.2 \mathrm{~Hz}, 4 \mathrm{H}), 7.51$ (m, J 31.2 $\mathrm{Hz}, 4 \mathrm{H}), 7.23$ (d, J $8.2 \mathrm{~Hz}, 4 \mathrm{H})$.

4,4"-Bis(p-octylphenyloxycarbonyl)-o-terphenyl (4). 4,4"-o-Terphenyl-dicarboxylic acid 2 (0.500 g; $1.57 \mathrm{mmol}), 4$-octylphenol (0.648 g; $3.14 \mathrm{mmol}), N, N^{\prime}$-dicyclohexylcarbodimide (0.648 $\mathrm{g} ; 3.14 \mathrm{mmol})$, and 4-dimethylaminopyridine $(0.038 \mathrm{~g} ; 0.31 \mathrm{mmol})$ were added to dichloromethane $(30 \mathrm{~mL})$. The reaction mixture was stirred overnight at room temperature. Then the mixture was diluted with dichloromethane $(70 \mathrm{~mL})$ and washed with distilled water $(70 \mathrm{~mL})$. Only the dichloromethane soluble fraction was collected, and dichloromethane was removed by evaporation using a rotator evaporator. The crude product was dried under vacuum and purified by column chromatography on silica gel with a mixture of hexane/ethyl acetate $(6: 1 \mathrm{v} / \mathrm{v})$. FT-IR (KBr pellet, $\mathrm{cm}^{-1}$ ): 3052 (Aromatic C-H stretch), 2927 (Aliphatic C-H stretch), 1733 (Conj. C=O stretch), 1608 (Aromatic $\mathrm{C}=\mathrm{C}$ stretch), 1264 (C-O-C symmetry stretch). ${ }^{1} \mathrm{H}$ NMR (400 MHz, $\mathrm{CDCl}_{3}, \delta$ in ppm): $8.07(\mathrm{~d}, J 8.16 \mathrm{~Hz}, 4 \mathrm{H}), 7.5(\mathrm{~d}, J 2.38 \mathrm{~Hz}, 4 \mathrm{H}), 7.28(\mathrm{t}, J 9.52 \mathrm{~Hz}, 4 \mathrm{H}), 7.22$ $(\mathrm{d}, J 8.5 \mathrm{~Hz}, 4 \mathrm{H}), 7.11(\mathrm{~d}, J 7.82 \mathrm{~Hz}, 4 \mathrm{H}), 2.62(\mathrm{t}, J 7.82 \mathrm{~Hz}, 4 \mathrm{H}), 1.62(\mathrm{~m}, 4 \mathrm{H}), 1.3(\mathrm{~d}, J 15.65$ $\mathrm{Hz}, 20 \mathrm{H}), 0.89$ (t, J 7.15 Hz, 6H). ${ }^{13} \mathrm{C} \mathrm{NMR} \mathrm{(100} \mathrm{MHz,} \mathrm{CDCl}_{3}, \delta$ in ppm): 165.1, 148.8, 146.4, $140,5,139.5$, 130.6, 130.0, 130.0, 129.3, 128.4, 128.0, 121.3, 35.4, 31.9, 31.4, 29.4, 29.3, 29.2, 22.6, 14.1. Elem. Anal.: Calc. for $\mathrm{C}_{48} \mathrm{H}_{54} \mathrm{O}_{4}$ : C 82.96, H 7.83; Found: C 81.67, H 8.31.

4,4"-Bis(p-hexyloxyphenyloxycarbonyl)-o-terphenyl (5). 4,4"-o-Terphenyl-dicarboxylic acid 2 $(0.500 \mathrm{~g} ; 1.57 \mathrm{mmol})$ and 4-(heptyloxy)phenol $(0.654 \mathrm{~g} ; 3.14 \mathrm{mmol}), \quad N, N^{\prime}-$ dicyclohexylcarbodimide $(0.648 \mathrm{~g} ; 3.14 \mathrm{mmol})$, and 4-dimethylaminopyridine $(0.038 \mathrm{~g} ; 0.31$ 
mmol) were dissolved in dichloromethane $(30 \mathrm{~mL})$. The reaction mixture was stirred overnight at room temperature. Then the mixture was diluted with dichloromethane $(70 \mathrm{~mL})$ and washed with distilled water $(70 \mathrm{~mL})$. Only the dichloromethane soluble fraction was collected, and dichloromethane was removed by evaporation using a rotator evaporator. The crude product was dried under vacuum and purified by column chromatography on silica gel with a mixture of hexane/ethyl acetate $(6: 1 \mathrm{v} / \mathrm{v})$. FT-IR $\left(\mathrm{KBr}\right.$ pellet, $\left.\mathrm{cm}^{-1}\right): 3062$ (Aromatic C-H stretch), 2932 (Aliphatic C-H stretch), 1738 (Conj. C=O stretch), 1608 (Aromatic C=C stretch), 1269-1245 (CO-C symmetry stretch). ${ }^{1} \mathrm{H}$ NMR (400MHz, $\mathrm{CDCl}_{3}, \delta$ in ppm): 8.04 (d, J $\left.8.42 \mathrm{~Hz}, 4 \mathrm{H}\right), 7.48$ (d, $J 2.52 \mathrm{~Hz}, 4 \mathrm{H}), 7.25(\mathrm{t}, J 8.53 \mathrm{~Hz}, 4 \mathrm{H}), 7.08(\mathrm{~d}, J 8.85 \mathrm{~Hz}, 4 \mathrm{H}), 6.90$ (d, J 9.1 Hz, 4H), $3.93(\mathrm{t}, J$ $6.63 \mathrm{~Hz}, 4 \mathrm{H}), 1.76(\mathrm{~m}, 4 \mathrm{H}), 1.43(\mathrm{~m}, 4 \mathrm{H}), 1.29(\mathrm{~m}, 12 \mathrm{H}), 0.88(\mathrm{t}, J 6.97 \mathrm{~Hz}, 6 \mathrm{H}) .{ }^{13} \mathrm{C} \mathrm{NMR}(100$ $\mathrm{MHz}, \mathrm{CDCl}_{3}, \delta$ in ppm): $165.4,156.9,146.5,144.2,139.5,130.6,130.0,129.9,128.4,128.0$, 122.3, 115.1, 68.4, 31.8, 29.2, 29.0, 26.0, 22.6, 14.1. Elem. Anal.: Calc. for $\mathrm{C}_{46} \mathrm{H}_{50} \mathrm{O}_{6}$ : C 79.05, H 7.21; Found: C 78.18, H 7.68.

\section{Acknowledgements}

This work was supported by NSF grant DMR-9971143.

\section{References}

1. Malliaras, G.; Friend, R. Physics Today 2005, 58, 53.

2. Heeger, A. J. in Conjugated Polymers and Related Materials, Salaneck, W. R.; Lundstrom, I.; Ranby, B., Edit. Oxford University Press 1993, 27.

3. Bronstein H. A.; Luscombe, C. K. J. Am. Chem. Soc. 2009, 131, 12894.

4. Dingemans, T. J; Bacher, A.; Thelakat, M.; Pedersen, L. G.; Samulski, E.T.; Schmidt, HW. Synthetic Metals 1999, 105, 171.

5. Zafiropoulos, N. A.; Choi, E-J.; Dingemans, T.; Lin, W.; Samulski, E. T. Chem. Mater. 2008, 20, 3821.

6. Kasashima, Y.; Yamamoto, K.; Ando, N.; Akutsu, F.; Naruchi, K.; Miura, M. Polym. J. 1994, 26, 1298.

7. Campbell, T. W. J. Am. Chem. Soc. 1960, 82, 3126.

8. $\quad$ Banfi, S.; Montanari, F.; Pozzi, G.; Quici, S. Tetrahedron 1994, 50, 9025.

9. Rossa, L.; Vögtle, F. Liebigs. Ann. Chem. 1981, 459.

10. (a) Wittek, M.; Vögtle, F Chem. Ber. 1982, 115, 1363. (b) Wong, T.; Yuen, M. S. M.; Mak, T. C. W.; Wong, H. N. C. J. Org. Chem. 1993, 58, 3118.

11. (a) Witteck, M.; Vögtle, F Chem. Ber. 1982, 115, 1363. (b) Watanabe, T.; Miyaura, N.; Suzuki, A. Synlett 1992, 207. (c) Satoh, T.; Inoh, J.; Kawamura, Y.; Kawamura, Y.; Miura, M. Nomura, M. Bull. Chem. Soc. Jpn. 1998, 71, 2239. 